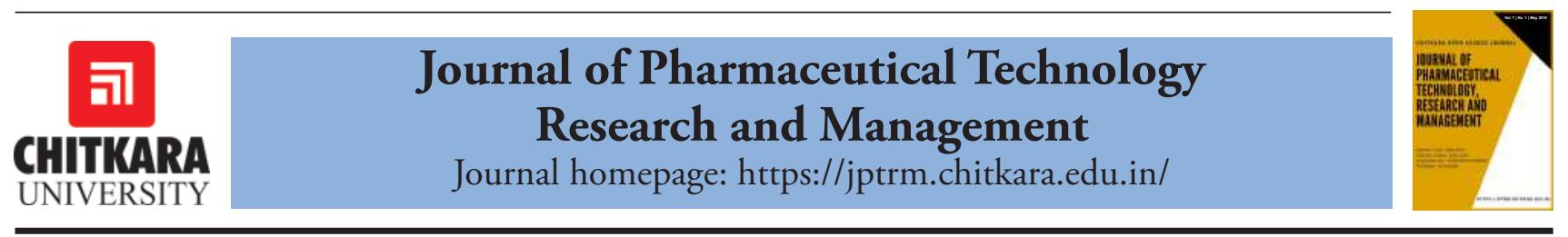

\title{
A Study of Prescription Practice for Drugs in Rural Area of Dehradun, Uttarakhand, Using WHO Indicators
}

\author{
Nautiyal Himani ${ }^{1 *}$, Bani Pankaj ${ }^{1}$, Prajapati Himani² and Shakir Saleem ${ }^{3}$ \\ ${ }^{1}$ Department of Pharmacology, Siddhartha Institute of Pharmacy, Dehradun, 248001, Uttarakhand, India. \\ ${ }^{2}$ Patient Safety Pharmacovigilance Associate, Department of Pharmacology, YSPGMC, Nahan, Sirmour, 173001, Himanchal Pradesh, \\ India. \\ ${ }^{3}$ Department of Pharmacology, Chitkara College of Pharmacy, Chitkara University, Rajpura, Punjab 140401, India
}

*Email:himanibpharma2011@gmail.com

\section{ARTICLE INFORMATION}

Received: Dec. 12, 2018

Revised: Feb. 20, 2019

Accepted: March 27, 2019

Published online: May 10, 2019

Keywords:

Prescription practice, North region, WHO indicators, India

\begin{abstract}
Background It has been seen in recent decades that there is a lot of development in the field of medicine all over the world. This leads to flooding of medicines in the market. Developing countries are also not behind in this regard but there is lack of standards at all levels for medical treatment. The health care delivery system should be improved to secure the quality of life. In the case of Indian markets, it is also consumed with more than 70,000 formulations, compared to approximately 350 formulations listed in the World Health Organization (WHO) Essential Drug List. Several studies conducted in different regions of India have reported that most prescriptions in India are of drugs with "unclear efficiency." Developing countries need to promote rational drug use which can be achieved by assessing the drug use patterns with the WHO drug use indicators

Objective The present study was conducted in a rural area of Dehradun to assess the medicine prescriptions patterns among health facilities in this area using WHO Medication Use indicators.

Material and Method: In this study, one hundred patients were interviewed about their socioeconomic statues along with complete medication history and ongoing medications, in a prescribed format. WHO guidelines were used for analyzing the data using Microsoft excel. The study was conducted in danda lakhond a rural area of Dehradun, Uttarakhand.

Result We encountered various astonishing results in this study. The gender ratio for the present study was (78:22) for male: female subjects. Socioeconomic status of the study population was significantly good concerning literacy as only $03 \%$ of people were illiterate. Total prescribed drug products were 152 ; this indicates that an average number of drugs per prescription was 1.52 . The generic drugs prescribed in this study were 113 which are $74 \%$ of the total number of drugs prescribed. When compared with (National List of essential medicines) of India nearly all prescribed drugs ( $n=152,98$ $\%$ ) were included in the list. The present study included 10 therapeutic categories of the Prescribed drug, most prescribed drugs ( $\mathrm{n}=34,34 \%$ ) were antibiotics in the study area and least prescribed drugs were antiviral drugs i.e. Only $(\mathrm{n}=03,3 \%)$.

Discussion The present study was an attempt to identify the prescribing pattern of drugs in a rural area of Dehradun Uttarakhand. A small study population was interviewed for this assessment. We concluded that prescription practices were good and WHO standards were followed in prescribing the medicines. Although, some parameters should also be corrected for WHO guidelines such as usage of antibiotics in prescriptions practices, average medicines prescribed per patient, and information regarding dosage form prescribed to patients.
\end{abstract}

\section{Introduction}

In developing countries, improvement in standards of medical treatment plays an important role in the health care delivery system [1]. The rational drug therapy is defined as the usage of a lesser number of drugs to obtain maximum effect in a smaller time with cost-effective manner. "The rational drug use pattern" is promoted by WHO drug use indicators [2]. These indicators are used to measure the utility of drugs in the health care system to describe patterns of drug use and the prescriber's behavior for dispensing. Multidrug prescription and its various complications can also be detected by these parameters [3]. The information gathered by these parameters can be utilized by general public concerning their clinical 
requirements, as per their own dosage requirements for an individual, for an appropriate time period, at the reasonable cost, this information can also be utilized by medical profession, public health administrators for further researches [1]. Several studies conducted in India itself have reported that most of the drugs marketed in India are of "unclear efficiency". The huge number of manufacturing and marketing of over the counter drugs which includes drug combinations, vitamins, and health tonics, which are specific to Indian market leads to a strong competition between manufacturers, this competition between manufacturers influence the prescribers to prescribe branded medicines as they are also getting benefits from them. The unethical competition results in the unnecessary prescription of drug combinations that are not rational [4, 5]. WHO has developed Medication Use Indicators; which includes indicators for Prescription to examine the provided services to the population regarding rationality [6]. For a given place we can determine the specifications regarding medicines with the help of Prescription Indicators. In this process, different parameters are compared and evaluated for the identification of medication needs and the most frequently used medications in that place. The pattern of prescription and quality of dispensing services to the population these can be identified by investigators by using these indicators.

Poly-medication or multi-drug combinations are identified by an average number of drugs per prescription. This is a major factor contributing to identifying drug interactions and adverse drug reactions. Generic drugs percentage in total prescriptions is calculated by the number of prescriptions of the drugs prescribing in their generic name, this information is used to evaluate the drug cost control in the health care system. This parameter also identifies the advertising influences on the medical personnel involved in prescribing medicines [6].

The national list of essential medicine (NLEM) was used to compare the percentage of prescribed drugs; this indicator was used to determine the deviation of prescription from the national formulary. This parameter also measures whether the current National Drug Policy (NDP) of October 1998 is being followed or not. The overall cost of medications in the general population is controlled and some mostly occurring diseases can be treated cost-effectively The rate of Antibiotics resistance can be evaluated by Percentage of antibiotic prescribed per patient [6]. Injectable drugs are also evaluated in terms of Percentage of prescribed injectable drugs, It helps to assess the quantity of injectable dispensing, Skilled administration is necessary with this route because wrong application may cause major side effects, in some cases it may cause injuries hypersensitivity reactions (anaphylactic reactions), adverse reactions and necrosis, etc. [6]. Several studies have performed based on these indicators, every parameter has not evaluated in a single study which leads to lacking some information, most of the study evaluated Indian prescription with "unclear efficiency" $[5,7,8]$. The developing countries face unavoidable problems due to unnecessary drug prescription; they are Due to the high cost of inappropriate use of drugs, developing countries face more problems due to short supply of economic sources and indefinite drug policy [9]. The Rational drug therapy is essential in developing countries, WHO indicators are used for the assessment of drug use pattern $[10,11]$ India is a developing country which is also dealing with these problems various studies has been conducted in the south region of India but there was no such study reported in north region of the country, so we are attempting to assess the patterns of drug use by using $\mathrm{WHO}$ core drug use and complementary indicators in Dehradun region of Uttarakhand, India.

\section{Materials and Method}

\subsection{Study Design}

This observational study was conducted in a rural area of Dehradun, Uttarakhand for a period of 4 weeks. The data was collected in a prescribed format which included patient information (Name, Age, sex, weight), occupation, education, income, history, diagnosis, drug information and other parameters. Total 100 prescriptions were evaluated, and the data was analyzed by using Microsoft excel.

\subsection{Data Collection}

The study population was selected by random sampling. The interviewed patients were called a sampling unit at a given rural area. All the data was collected in a specific data collection form prepared for this study as per the data requirement. The patients were interviewed, and their prescriptions were observed for data collection. WHO complementary indicators were used in this regard. Along with medication information, socioeconomic status of patients was also analyzed by obtaining the Information like date of prescription, sex, age, and educational qualification and medication information such as types of dosage forms and the number of drugs per prescription.

\subsection{Prescribing Indicators Measurement}

The WHO prescribing indicators are certain formulas which are taken from the manual of $\mathrm{WHO}$ for the assessment in this study are as follows:

1. Average number of drugs per prescription $=$ Total number of drugs prescribed/Total number of patients.

2. Percentage of generic drugs prescribed $=$ (Number of generic drugs prescribed/ Total number of drugs prescribed) $\times 100$.

3. Percentage of an antibiotic prescribed per patient $=$ (Number of patient prescribed with an antibiotic/ Total number of patients sampled) $\times 100$. 
4. Percentage of an injections prescribed per patient $=$ (Number of patient prescribed with an injection /Total number of patients sampled) $\times 100$.

5. Percentage of prescribed drugs from essential drugs list $=$ (Number of prescribed drugs from essential drugs list/Total number of prescribed drugs) $\times 100$.

\subsection{Data Analysis}

All the data were analyzed using Microsoft Excel 2007. The results were reported as an average and percentage.

\section{Result}

Total 100 prescriptions were evaluated over a period of 1 month in this study; the population-based attributes are shown in graph 1 . Out of 100 patients who were included in the study $(\mathrm{n}=78,78 \%)$ were male and $(\mathrm{n}=22,22 \%)$ were female. Most of the study subjects belonged to the age of 2039 years (32.4\%). The mean age in female patients was 33.6土 8.48 (SD) with a mean weight of $65.47 \pm 11.64$ (SD). Among the male patients the mean age was $39.3 \pm 8.92$ (SD) with a mean weight of $70.84 \pm 9.86$ (SD). Total ten parameters were accessed for the prescription audit. From the table we can predict that in total 100 samples of prescription audit.

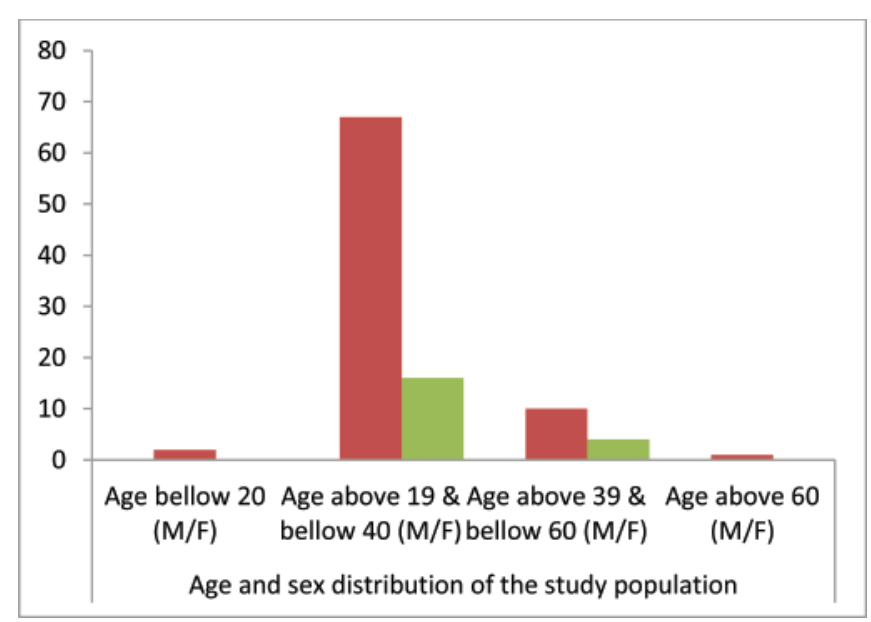

Figure 1. Age and Sex Distribution of the Study Population

Table 1. Age and Sex Distribution of the Study Population

\begin{tabular}{lllll}
\hline S. & \multicolumn{4}{l}{ Age and sex distribution of the study population } \\
\cline { 2 - 5 } No & $\begin{array}{l}\text { Age } \\
\text { below } 20 \\
(\mathrm{M} / \mathrm{F})\end{array}$ & $\begin{array}{l}\text { Age above } \\
\mathbf{1 9} \text { \& below } \\
\mathbf{4 0}(\mathrm{M} / \mathrm{F})\end{array}$ & $\begin{array}{l}\text { Age above 39 } \\
\mathbf{8} \text { below } \mathbf{6 0} \\
(\mathrm{M} / \mathrm{F})\end{array}$ & $\begin{array}{l}\text { Age above } \\
\mathbf{6 0}(\mathrm{M} / \mathrm{F})\end{array}$ \\
\hline 1. & 2 & 67 & 10 & 1 \\
2. & 0 & 16 & 4 & 0 \\
\hline
\end{tabular}

Under the Socioeconomic status of patients, the educational status indicates majority of person were literate to the level of graduation i.e. $(n=44,44 \%)$ and only $(n=3,03 \%)$ people were illiterate. Remaining population were in between theseeducational levels i.e. Primary, Middle high school, High school, Intermediate 6\%, 9\% ,9\%, 29\% respectively (Table II and Graph no. 02 ).

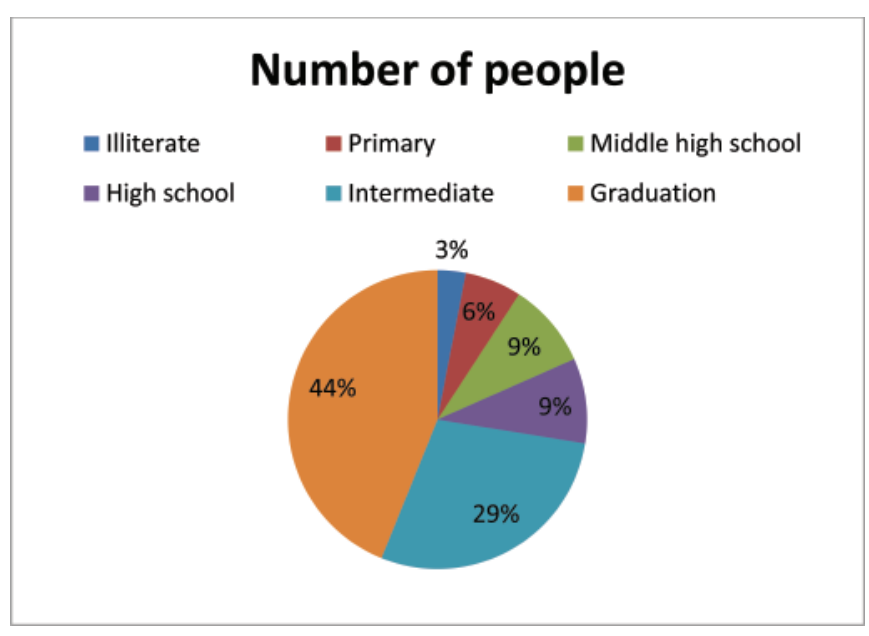

Figure 2. Educational Status of Study Population

Table 2. Educational Status of Study Population

\begin{tabular}{llll}
\hline $\begin{array}{l}\text { S. } \\
\text { No. }\end{array}$ & Educational level & Number of people & $\%$ population \\
\hline 1. & Illiterate & 03 & $3 \%$ \\
2. & Primary & 06 & $6 \%$ \\
3. & Middle high & 09 & $9 \%$ \\
& school & & \\
4. & High school & 09 & $9 \%$ \\
5. & Intermediate & 29 & $29 \%$ \\
6. & Graduation & 44 & $44 \%$ \\
\hline
\end{tabular}

Out of 100 patients interviewed majority of population were unemployed $\mathrm{n}=47(47 \%)$ which mostly included females and older patients. For other criteria such as self-employed, worker, clerical work, professional work the percentage people included $21 \%, 11 \%, 19 \%, 2 \%$ respectively (Table III and Graph no. 03).

Table 3. Occupational Level of Study Population

\begin{tabular}{llll}
\hline $\begin{array}{l}\text { S. } \\
\text { No. }\end{array}$ & Occupational Level & Number of People & $\begin{array}{l}\% \\
\text { Population }\end{array}$ \\
\hline 1. & Unemployed & 47 & $47 \%$ \\
2. & self-employed & 21 & $21 \%$
\end{tabular}




\begin{tabular}{llll} 
3. & Worker & 11 & $11 \%$ \\
4. & Clerical work & 19 & $19 \%$ \\
5. & Professional work & 02 & $2 \%$ \\
\hline
\end{tabular}

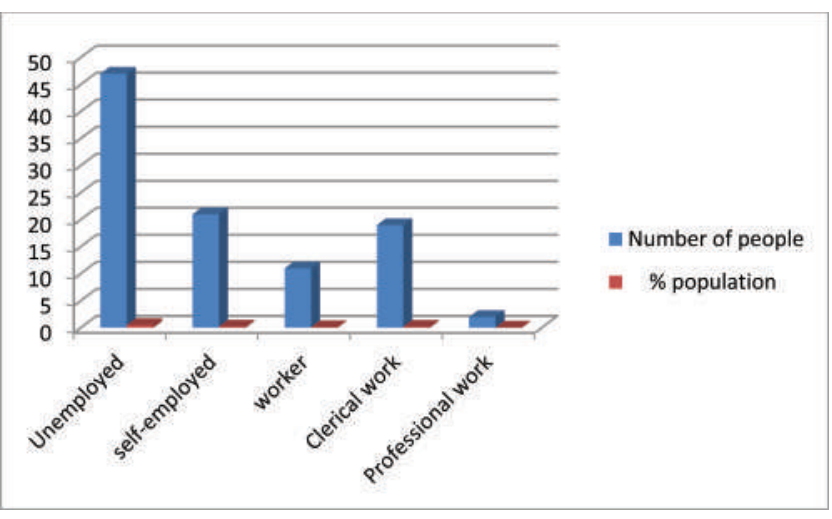

Figure 3. Occupational Level of Study Population

During evaluating the economic status of study population, we found most of the people were with No Income i.e. $\mathrm{n}=49$ (49\%). Remaining populations were also with average economic condition as maximum $(\mathrm{n}=21,21 \%)$ were earning $(10000-20000)$ rupees per month. Other people encountered for economicstatus with per month salary $(1000-10000)(\mathrm{n}=10,10 \%)$, (20000-30000) $\mathrm{n}=16$ (16\%), (30000-40000) $\mathrm{n}=03$ $(3 \%)$. Only $(n=1,1 \%)$ people were with satisfactory economic condition (40000-50000) (Table IV and Graph no. 04).

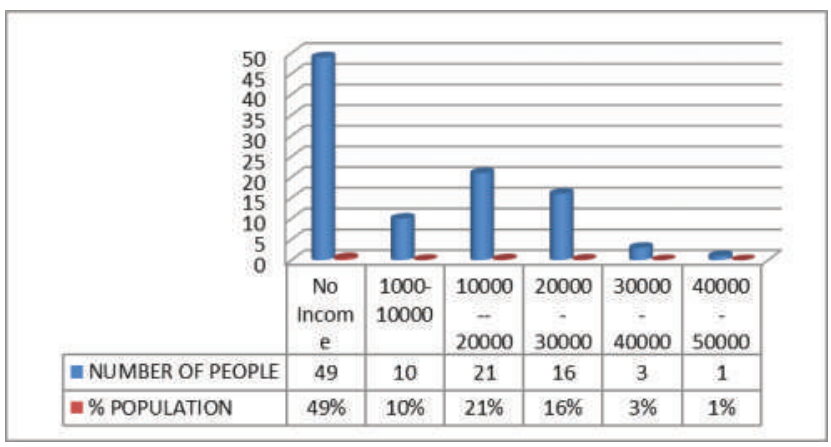

Figure 4. Economic Status of Study Population

Table 4. Economic Status of Study Population

\begin{tabular}{llll}
\hline $\begin{array}{l}\text { S. } \\
\text { No. }\end{array}$ & Economic Status & Number of People & $\%$ Population \\
\hline 1. & No Income & 49 & $49 \%$ \\
2. & $1000-10000$ & 10 & $10 \%$
\end{tabular}

\begin{tabular}{llll} 
3. & $10000-20000$ & 21 & $21 \%$ \\
4. & $20000-30000$ & 16 & $16 \%$ \\
5. & $30000-40000$ & 03 & $3 \%$ \\
6. & $40000-50000$ & 01 & $1 \%$ \\
\hline
\end{tabular}

Out of 100 patients only $(n=22,22 \%)$ showed history with alcohol intake and $(n=25,25 \%)$ were smoker for earlier time (Table V and Graph no. 05).

Table 5. History Status of Study Population

\begin{tabular}{llll}
\hline S.No & History & No of People & $\%$ Population \\
\hline 1. & Alcoholic & 22 & $22 \%$ \\
2. & Smoker & 25 & $25 \%$ \\
3. & Allergic & 00 & $0 \%$ \\
4. & Other Medicine & 00 & $0 \%$ \\
\hline
\end{tabular}

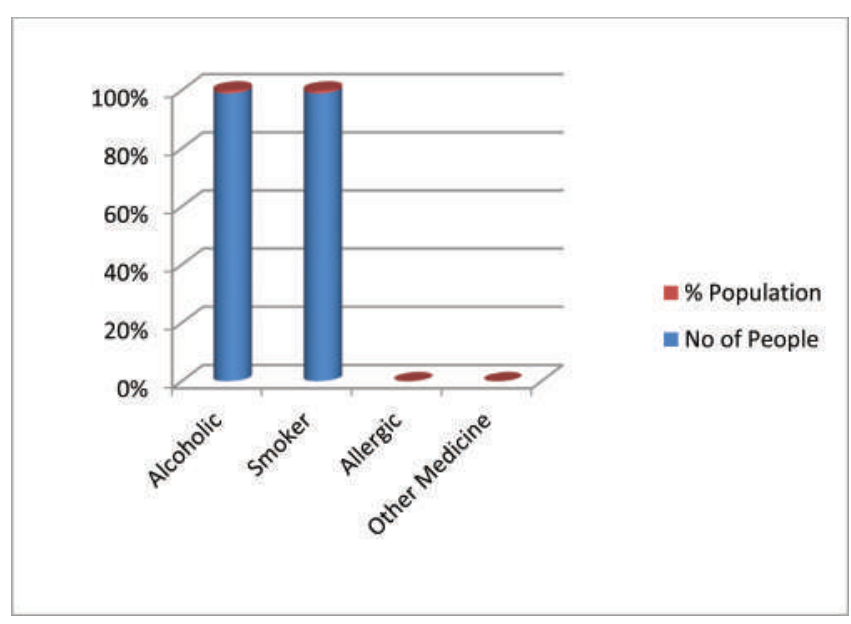

Figure 5. History Status of Study Population

During evaluating the morbidity pattern in study population, we found majority of population dealing with respiratory diseases $(n=25,25 \%)$. The study results showed morbidity pattern for other diseases encountered Pain Related Problems $(n=15,15 \%)$, CNS Related Problem $(n=13$, $13 \%)$, Genitourinary Problem $(n=08,8 \%)$, Skin Problem $(\mathrm{n}=07,7 \%)$, Endocrinology and Infections $(\mathrm{n}=06,6 \%)$, CVS Related Problem ( $\mathrm{n}=05,5 \%)$ other problems which were not included in above categories $(\mathrm{n}=07,7 \%)$ (Table VI and Graph no. 06).

Table 6. Morbidity Pattern of Study Population

\begin{tabular}{llll}
\hline S.No & Disease Pattern & $\begin{array}{l}\text { Number of } \\
\text { People }\end{array}$ & $\begin{array}{l}\% \\
\text { Population }\end{array}$ \\
\hline 1. & CNS Related Problem & 13 & $13 \%$ \\
2. & CVS Related Problem & 05 & $5 \%$
\end{tabular}




$\begin{array}{llll}\text { 3. } & \text { Respiratory Related } & 25 & 25 \% \\ \text { 4. } & \text { Gastrointestinal Problem } & 05 & 5 \% \\ \text { 5. } & \text { Pain Related Problem } & 15 & 15 \% \\ \text { 6. } & \text { Genitourinary Problem } & 08 & 8 \% \\ \text { 7. } & \text { Skin Problem } & 07 & 7 \% \\ \text { 8. Joint Disorder } & 03 & 3 \% \\ \text { 9. } & \text { Endocrinology } & 06 & 6 \% \\ \text { 10. } & \text { Infections } & 06 & 6 \% \\ \text { 11. } & \text { Others } & 07 & 7 \%\end{array}$

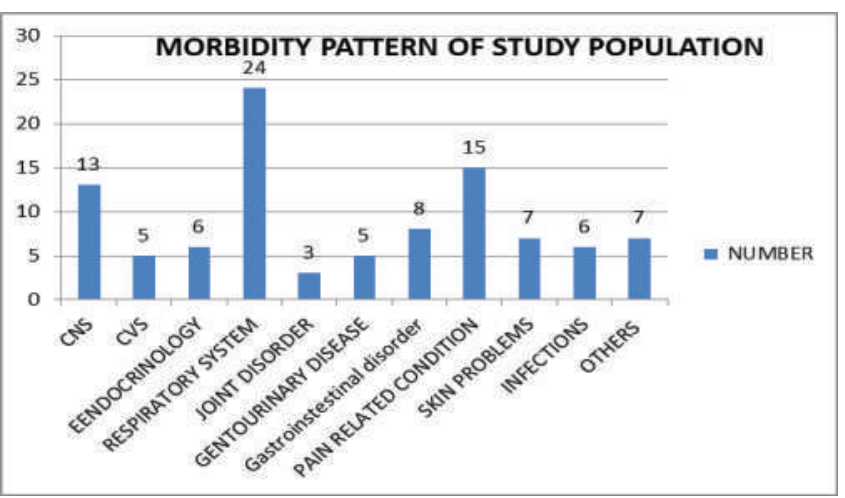

This study population was prescribed with 152 drug products. This finding indicates that an average number of drugs per prescription were 1.52 which vary between 1 and 6 . The drugs prescribed by generic name were $(\mathrm{n}=113,74 \%) .18$ patients $(18 \%)$ prescribed with an antibiotic. National list for essential medicine (NLEM) was used for comparison and it was observed that all of the drugs used in prescription $(\mathrm{n}=152,100 \%)$ were included in this list.The drugs prescribed per prescription was also analyzed in this study and it was observed that Majority of the prescriptions were prescribing $(\mathrm{n}=1$, $43 \%),(n=2,38 \%)$ and $(n=3,18 \%)$ drugs in them. It was also found that only $1 \%$ prescriptions were prescribing maximum number of drugs $(n=4)$ in the prescription. In our study period, different therapeutic classes were being prescribed to the patients, we calculated the percentage of each therapeutic class in the prescriptions and it was found that total 10 categories were used in prescription. The $34 \%$ of drugs were from antibiotic category which was maximum $(\mathrm{n}=34)$ prescribed drug. The pain killers especially NSAIDS $(\mathrm{n}=27,27 \%)$ were in second position which was prescribed during study, and it was surprising that Drugs acting on CNS ( $\mathrm{n}=26,26 \%)$ were also mostly prescribing drug instead of it was a rural area. Only 3\% antiviral drugs were prescribed holding the last position (Table VII and Graph 7).

Table 6. Morbidity Pattern of Study Population

Table 7. Therapeutic Pattern of Drug Prescribed on Study Population Reference to Generic vs. Branded Drugs

\begin{tabular}{|c|c|c|c|c|c|c|}
\hline $\begin{array}{l}\text { S. } \\
\text { No }\end{array}$ & $\begin{array}{l}\text { Therapeutic } \\
\text { classification }\end{array}$ & $\begin{array}{l}\text { No. of times for } \\
\text { Total Prescription }\end{array}$ & $\begin{array}{l}\text { No. of times generic } \\
\text { drugs prescription }\end{array}$ & $\begin{array}{l}\% \text { of generic drugs } \\
\text { prescription }\end{array}$ & $\begin{array}{l}\text { No. of times Branded } \\
\text { Drugs prescription }\end{array}$ & $\begin{array}{l}\% \text { of Branded } \\
\text { Drugs prescription }\end{array}$ \\
\hline 1. & Antibiotics & 34 & 34 & $100 \%$ & 00 & $00 \%$ \\
\hline 2. & $\begin{array}{l}\text { Drugs acting on } \\
\text { CNS }\end{array}$ & 26 & 24 & $92.3 \%$ & 02 & $07 \%$ \\
\hline 3. & NSAIDS & 27 & 19 & $70.03 \%$ & 08 & $29.62 \%$ \\
\hline 4. & Antihypertensive & 08 & 00 & $00 \%$ & 08 & $100 \%$ \\
\hline 5. & Antihistaminic & 10 & 10 & $100 \%$ & 00 & $00 \%$ \\
\hline 6. & Antifungal & 08 & 06 & $75 \%$ & 02 & $25 \%$ \\
\hline 7. & $\begin{array}{l}\text { Endocrinological } \\
\text { drugs }\end{array}$ & 13 & 08 & $61.53 \%$ & 05 & $38.46 \%$ \\
\hline 8. & $\begin{array}{l}\text { Respiratory } \\
\text { medicines }\end{array}$ & 15 & 03 & $20 \%$ & 12 & $80 \%$ \\
\hline
\end{tabular}



9. steroids
08
08
$100 \%$
00
$00 \%$
10. Antiviral drugs
03
01
$33 \%$
02
$66 \%$

Table 8. Drug Information based on Dosage Form Route of Administration and Frequency of Dosing

\begin{tabular}{|c|c|c|c|c|c|c|c|c|c|}
\hline \multirow{2}{*}{$\begin{array}{l}\text { S. } \\
\text { No. }\end{array}$} & \multicolumn{3}{|l|}{ Dosage form } & \multicolumn{3}{|c|}{ Route of administration } & \multicolumn{3}{|c|}{ Frequency of dosing } \\
\hline & Dosage form & $\begin{array}{l}\text { No. of times } \\
\text { prescribed }\end{array}$ & $\begin{array}{l}\% \\
\text { prescribed }\end{array}$ & Route & $\begin{array}{l}\text { No. of times } \\
\text { Used route }\end{array}$ & $\begin{array}{l}\% \text { Used } \\
\text { route }\end{array}$ & Frequency & $\begin{array}{l}\text { No. of } \\
\text { times }\end{array}$ & $\begin{array}{l}\% \text { Frequency } \\
\text { of dosing }\end{array}$ \\
\hline 1 & Tablet & 96 & 90.56 & Oral & 96 & $90.56 \%$ & 2 times a day & 90 & $90 \%$ \\
\hline 2. & Parenteral & 03 & $2.83 \%$ & I.V & 02 & $1.88 \%$ & 3 times a day & 02 & $2 \%$ \\
\hline 3. & Topical & 03 & $2.83 \%$ & I.M & 02 & $1.88 \%$ & once a day & 06 & $6 \%$ \\
\hline 4. & Liquid & 02 & $1.88 \%$ & S.C & 04 & $3.77 \%$ & Every 8 & 01 & $1 \%$ \\
\hline 5. & powder & 02 & $1.88 \%$ & Topical & 03 & $2.83 \%$ & $12 \mathrm{~h}$ & 01 & $1 \%$ \\
\hline
\end{tabular}

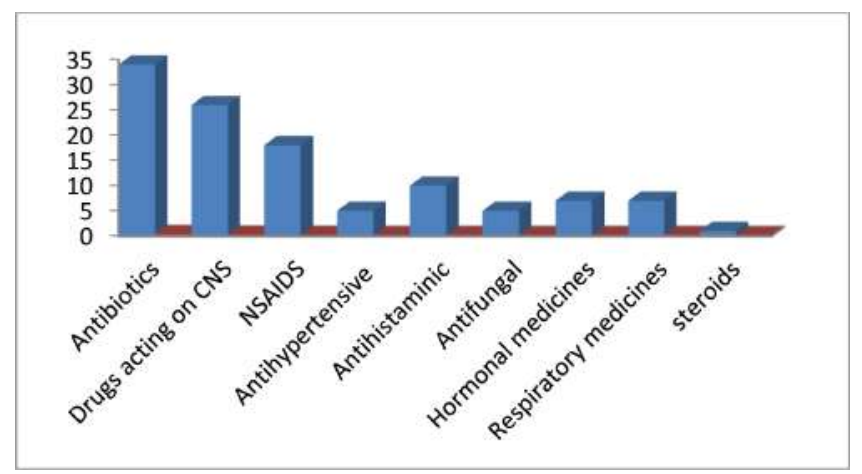

Figure 7. Therapeutic Pattern of Drug Prescribed on Study Population

There were 5 categories of Dosage form prescribed in our study which includes tablet, parenteral, topical, liquid, and powder, the percentages of dosage form prescription was found to be for tablet, parenteral, topical ,liquid, powder were $90 \%, 2.83 \%, 2.83 \%, 1.88 \%, 1.88 \%$ respectively (Table VIII and Graph 8).

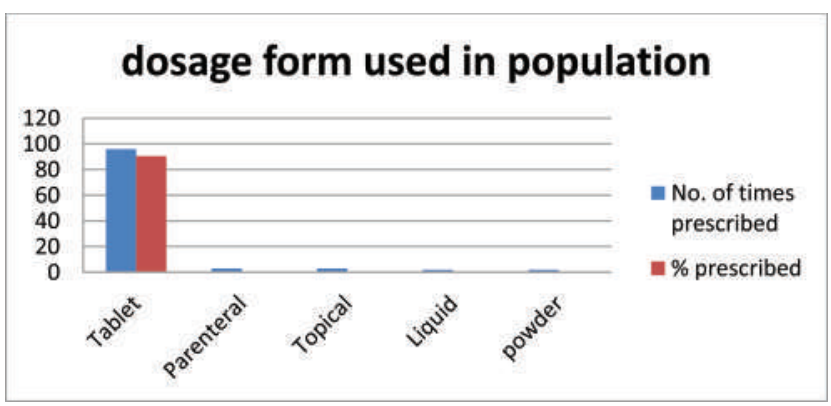

Figure 8. Drug Information based on Dosage Form
The route of administration used for drug intake was also evaluated in the prescription which indicated that the oral route was mostly prescribed, and topical route was least prescribed route of administration. The percentages of drugs prescribed by different routes were Oral, I.V, I.M, S.C, Topical were $90.56 \%, 1.88 \%, 1.88 \%, 3.77 \%, 2.83 \%$ respectively (Table VIII and Graph 9).

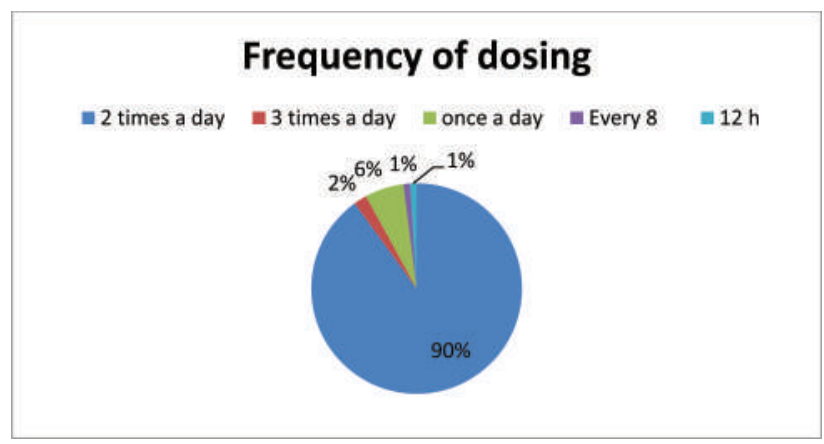

Figure 9. Drug Information based on Frequency of Dosing

\section{Discussion}

The WHO recommended the value for an average number of drugs prescribed per patient is (1.3-2.0) our study fulfill this requirement as the average number of prescription was found 1.5 with a maximum of 4 drugs prescribed, so the results are acceptable [12]. Different studies have also encountered this parameter when compared with those studies at national and international front we find that our result showing Average number of drugs prescribed is lesser than them, such as mentioned in national research Raj et al. (4.98) and Upadhyay et al. (3.76), and studies in other 
countries such as Shankar et al. (3.39), Wang et al. (3.52), Xinyi et al. Baotou, Inner Mongolia (2.7), Lianzhen et al. Beijing (2.63), Hua et al. Guangdong (2.36), Daohai et al. Guangxi (1.95) provinces and Bimo Nigeria (3.8) [1, 12, 17]. While comparing with other studies it was found that our study encounters a higher average number of drugs per patients such as to Sudan (1.4) and Zimbabwe (1.3) [20-21].

The generic drugs are those pharmaceutical drugs that contain the same active pharmaceutical ingredient as a drug containing in patent products. These preparations are cheap in price as compared to the original drug, so the maximum number for generic drug prescription indicates about the socioeconomic status of the population as well as the locality of the study area. In our study, $74 \%$ of generic drugs are prescribed which a large proportion is and not so far from the standard $100 \%$ [22]. This higher percentage of generic drug prescription confirms that this area is rural and due to the socioeconomic status of population generic drugs are mostly prescribed when compared with branded drugs. Ethiopia [23], as well as Uganda [24] has been reported similar findings in other studies.

Antimicrobial resistance is a distracted emergency which is resulted due to excessive usage of antibiotics. It is very commonly seen in general practices that antibiotics are very commonly being prescribed to treat the viral infections and various other ailments which should not be treated with any antibiotics. These improper practices regarding antibiotic usage lead to serious complications of resistance and microbes are unable to be treated as they are converting in terrible life-threatening modifications [23]. In our study, $34 \%$ of antibiotics were prescribed that is not so far from the standard (20-26.8) [22]. When compared with some international studies it was found higher than Yemen (24.6\%), Saudi Arabia (20\%) and China (29.9\%) [12, 29-30] which indicates the dispensing of antibiotics needs to be observed in this area. Some studies have shown that it was lower than Laos (47\%), Sri Lanka (47\%), Zimbabwe (58\%), South Ethiopia (58\%) and Nigeria (72.8\%). (23, 25, 26,27, 31, 32].

Polypharmacy is an unfavorable prescription habit which shows lack of clinical practice and insufficient training of health care individuals. Some other variables also play a key role in this kind of dispensing such as lack of proper management in the health care system, dissimilarity in the status of the population as well as their disease and transience profile [22].

The National list of essential medicine (NLEM) was used to compare the percentage of drugs prescribed our study. It was found that almost every drug (99.99\%) was available in the list and the prescribers were mostly following national guidelines for their prescription practice in Dehradun (India). The result was similar when compared with other studies such as in south Ethiopia (99.6) and is undifferentiated with the standard $(100 \%)$ which serves as ideal, [22].

\section{Conclusion}

The finding of this study suggests, the standard endorsed by WHO are not completely followed in prescribing antibiotic and generic drugs. Antibiotics are mostly prescribed drugs in our study; Antibiotic resistance is very common in developing countries due to their excessive usage. The present study concludes to monitor antibiotics usage to avoid resistance. Prescribers should follow the updated government guidelines which could be beneficial in improving rational drug use. Almost every hospital has its own Drug information centers and drug bulletins in India along with government bulletins which contain updated information about medicines. The general practices should refer to this information from time to time. Because in most of the cases the public goes to these practices for their ailment. This study population has a good literacy level but still needs to improve their knowledge about drugs and their usages. Almost every drug was prescribed according to a national list of essential medicine in respect of uses of injection, generic drugs prescribing this was not far from guidelines This small population-based study could contribute a data to be further used by researchers to improve drug prescription practices at the studied health centers.

\section{References}

[1] Shankar, R., Partha, P., Shenoy, N. (2000). Prescribing Patterns Of Drugs Among Patients Admitted With Cardiovascular Disorders In The Internal Medicine Ward: Prescribing Patterns In Inpatients. The Internet Journal of Internal Medicine, 3(1).

[2] Gross, F. (1981). Drug utilization - theory and practice. The present situation in the Federal Republic of Germany. Eur J Clin Pharmacol, 19(6), 387-394. https://doi.org/10.1007/BF00548580

[3] WHO. (1993). Action Programme for Essential Drugs. How to Investigate Drug use in Health Facilities. Geneva, Resource document. WHO Essential Medicines and Health Products Information Portal. tablt https://apps.who.int/medicinedocs/en/d/ Js2289e/8.3.html. Accessed 23march 2018.

[4] Srinivas, S. (2004). A network for the rational and ethical use of drugs. Indian J Med Ethics, 1, 13-14. https://doi.org/10.20529/IJME.2004.005 
[5] Linden, M., Lecrubier, Y., Bellantyono, C., Benkert, O., Kisely, S., Simon, G. (1999). The prescribing of psychotropic drugs by primary care physician: An international collaborative study. J Clin Psychopharmacol, 19, 132-140. https://doi.org/10.1097/00004714-199904000-00007

[6] Vooss, A.T., Diefenthaeler, H. S. (2011). Evaluation of prescription indicators established by the WHO in Getulio Vargas - RS. Braz J Pham Sci, 47(2), 385-390. https://doi.org/10.1590/S1984-82502011000200020

[7] Bhargava, A., et al. (2013). The crisis in access to essential medicines in India: key issues which call for action. Indian J Med Ethics, 10(2), 86-95. https://doi.org/10.20529/IJME.2013.028

[8] Patel, V., et al. (2005). Irrational drug use in India: a prescription survey from Goa. J Postgrad Med, 51(1), 9-12.

[9] Kshirsagar, M. J., Langade, D., Patil, S., Patki, P.S. (1998). Prescribing patterns among medical practitioners in Pune, India. Bull World Health Organ, 76, 271-275.

[10] Hogerzeil, H. V., Bimo, Ross-Degnan D., Laing, R. O., Ofori-Adjei D, Santoso, B., Azad Chowdhury, Das, A, K., Kafle, A. M., Mabadeje, A. F.(1993). Field tests for rational drug use in twelve developing countries. Lancet, 342 (8884), 1408-1410. https://doi.org/10.1016/0140-6736(93)92760-Q

[11 Chandelkar, U. K., Rataboli, P. V. (2014). A study of drug prescribing pattern using WHO prescribing indicators in the state of Goa, India. Int J Basic Clin Pharmacol, 3(6), 1057-1061.

https://doi.org/10.5455/2319-2003.ijbcp20141221

[12] Wang, H., Li, N., Zhu, H., Xu, S., Lu, H., Feng, Z. (2013). Prescription pattern and its influencing factors in Chinese county hospitals: A retrospective crosssectional study. PLoS One, 8(5), e63225. https://doi.org/10.1371/journal.pone.0063225

[13] Upadhyay, D. K., Palaian, S., Ravi Shankar, P., Mishara, P., Sah, A. K. (2007). Prescribing pattern in diabetic outpatients in a tertiary care teaching hospital in Nepal. J Med Diagn Res, 1(4), 248-255.

[14] Raj, K., Kamlesh, K., Kajal, H. L. (2013). A study of drug prescribing pattern and cost analysis among diabetic patients in a tertiary care teaching institute in North India. J Drug Deliv Ther, 3(2), 56-61. https://doi.org/10.22270/jddt.v3i2.431

[15] Xinyi, Z., Ruidong, H., Gang, H. (2010). Evaluation and analysis on 507 cases of outpatients prescription in hospital. Chin J Pharmacovigil, 7(12), 755-757. https://doi.org/10.1080/14719037.2010.515769
[16] Lianzhen, C., Shujie, W., Qing, W., Limin, S., Hailian, W., et al. (2003). Field survey of international RDU indicators. China Pharm, 14(3), 156-158.

[17] Hua, L., Hongwei, W., Danyang, W. (2009). Analysis of basic indicators and rational drug use: review of 6000 outpatient prescriptions. Eval Anal Drug-Use Hosp China, 9(4), 280-281.

[18] Daohai, C., Hua, L., Taotao. L. (2012). Evaluation of basic indicators in outpatient prescriptions and analysis of rationality in drug use. Eval Anal Drug-Use Hosp China, 12(4), 373-375.

[19] Bimo: Report on Nigerian field test. INRUD News (1992) 3(1), 9-10. In: How to Investigate Drug Use in Health Facilities. Geneva: WHO; 1993:74 (WHO/ DAP/93.1).

[20] Bannenberg, W. J., Forshaw, C. J., Fresle, D., Salami, A. O., Wahab, H. A. Evaluation of the Nile Province Essential Drug Project. Geneva: WHO; 1991. WHO/ DAP/91.10. In: How to Investigate Drug Use in Health Facilities. Geneva: WHO; 1993:74 (WHO/ DAP/93.1).

[21] Ministry of Health/Zimbabwe Essential Drugs Action Programme: essential Drugs Survey. In: How to Investigate Drug use in Health Facilities. Geneva: WHO; 1993:74 (WHO/DAP/93.1

[22] Isah, A. O., Ross-Degnan, D., Quick, J., Laing, R., Mabadeje, A.F.B. The development of standard values for the WHO drug use prescribing indicators. ICUM/ EDM/WHO. Available at http://www.archives.who. int/prduc2004/rducd/ICIUM_Posters/1a2_txt.html.

[23] Desalegn, A. (2013). Assessment of drug use pattern using WHO prescribing indicators at Hawassa University teaching and referral hospital, south Ethiopia: a cross-sectional study. BMC Health Serv Res, 13, 170.

https://doi.org/10.1186/1472-6963-13-170

[24] Christensen, R. F. (1990). A strategy for the improvement of prescribing and drug use in rural health facilities in Uganda. Ugandan Essential drugs and management program; 2 September-11 October 1990. In how to investigate drug use in health facilities. Geneva: WHO; 1993.74(WHO/ DAP/93.1).

[25] Mahajan, R., Singh, N. R., Singh, J., Dixit, A., Jain, A., Gupta, A. (2010). Current scenario of attitude and knowledge of physicians about rational prescription: a novel cross-sectional study. J Pharm Bioallied Sci, 2(2), 132-136. https://doi.org/10.4103/0975-7406.67008

[26] Menik, H. L., Isuru, A. I., Sewwandi, S. (2011). A survey: precepts and practices in drug use indicators at Government Healthcare Facilities: a hospital-based 
prospective analysis. J Pharm Bioallied Sci, 3(1), 165-169. https://doi.org/10.4103/0975-7406.76502

[27] Keohavong, B., Syhakhang, L., Sengaloundeth, S., Nishimura, A., Ito, K. (2006). Rational use of drugs: prescribing and dispensing practices at public health facilities in Lao PDR. Pharmacoepidemiol Drug Saf, 15(5), 344-347. https://doi.org/10.1002/pds.1169

[28] Assessment of the Pharmaceutical Sector in Ethiopia. Addis Ababa; 2003. Available at http://www. who.int/medicines/areas/coordination/ethiopia_ pharmaceutical.pdf.

[29] Bashrahil, K. A. (2010). Indicators of rational drug use and health services in Hadramout, Yemen. East Mediterr Health J, 16(2), 151-155. https://doi.org/10.26719/2010.16.2.151

[30] Irshaid, Y. M., Al-Homrany, M. A., Hamdi, A. A., Adjepon-Yamoah, K. K., Mahfouz, A. A. (2004).
A pharmacoepidemiological study of prescription pattern in outpatient clinics in Southwestern Saudi Arabia. Saudi Med J, 25(12), 1864-1870.

[31] Uzochukwu, B. S., Onwujekwe, O. E., Akpala, C. O. (2002). Effect of the Bamako-initiative drug revolving fund on availability and rational use of essential drugs in primary health care facilities in south-east Nigeria. Health Policy Plan, 17(4), 378-383. https://doi.org/10.1093/heapol/17.4.378

[32] Trap, B., Hansen, E. H., Hogerzeil, H. V. (2002). Prescription habits of dispensing and non-dispensing doctors in Zimbabwe. Health Policy Plan, 17(3), 288-295. https://doi.org/10.1093/heapol/17.3.288

[33] Ofori-Adjei, D. (1993). Report on Tanzanian field test. INRUD News; 3(1), 9. In: How to Investigate Drug Use in Health Facilities. WHO: Geneva, 74 (WHO/DAP/93.1). 